\title{
LncRNA ANRIL Regulates Ovarian Cancer Progression and Tumor Stem Cell-Like Characteristics via miR-324-5p/Ran Axis [Retraction]
}

\author{
Wang K, Hu YB, Zhao Y, Ye C. Onco Targets Ther. \\ 2021;14:565-576.
}

The Editor and Publisher of OncoTargets and Therapy wish to retract the published article. It was bought to the journal's attention that several figures within the article appeared to have duplicated images, specifically:

- Figure 4E panel $0 \mathrm{~h}$ si-ANRIL R2 appears to be duplicated with Figure $4 \mathrm{E}$ panel $0 \mathrm{~h} \mathrm{miR}$ $\mathrm{NC}$.

- Figure 5A panel si-NC appears to share duplicated regions with Figure 5A panel miR-NC.

- Figure 5C row ALDH CD133, the far left and centre right flow cytometry panels appear to show duplicated regions.

- Figure 5C row ALDH CD133, the centre left and far right flow cytometry panels appear to show duplicated regions.

- Figure 5C row CD117 CD44, the far left and centre right flow cytometry panels appear to show duplicated regions.

- Figure 5C row CD117 CD44, the centre left and far right flow cytometry panels appear to show duplicated regions.
- Figure 5C row Notch1 CD24, the far left and centre right flow cytometry panels appear to show duplicated regions.

- Figure 5C row Notch1 CD24, the centre left and far right flow cytometry panels appear to show duplicated regions.

- Figure 6D panel si-NC appears to share duplicated regions with Figure 6D panel si-ANRIL R2+pcDNARan.

- Figure 6D panel si-ANRIL R2 appears to share duplicated regions with Figure 6D panel si-ANRIL R2 + pcDNA.

The authors were unable to provide a satisfactory explanation for the alleged duplication and were unable to provide the original images used in the figures. The editor determined the findings of the article were no longer valid and requested for the article to be rejected.

Our decision-making was informed by our policy on publishing ethics and integrity and the COPE guidelines on retraction.

The retracted article will remain online to maintain the scholarly record, but it will be digitally watermarked on each page as "Retracted".
OncoTargets and Therapy is an international, peer-reviewed, open access journal focusing on the pathological basis of all cancers, potential targets for therapy and treatment protocols employed to improve the management of cancer patients. The journal also focuses on the impact of management programs and new therapeutic agents and protocols on patient perspectives such as quality of life, adherence and satisfaction. The manuscript management system is completely online and includes a very quick and fair peer-review system, which is all easy to use. Visit http://www.dovepress.com/

testimonials.php to read real quotes from published authors. 